\title{
Engaging junior doctors in our trust's medical leadership and management
}

\author{
Author: Anna Farris
}

Aim

To increase awareness of the importance of good leadership and senior hospital executive roles among junior doctors, in order to improve engagement and promote development of future clinical leaders in the NHS

\section{Methods}

A 1-day event focusing on leadership and management for senior registrars was organised. The event was open to senior registrars (ST5 and above) in all specialties at University Hospital Southampton, a large university teaching hospital and tertiary referral centre. Speakers were specifically chosen from senior trust executive staff and the senior consultant body to talk about relevant aspects of healthcare management and leadership, and their career pathways.

\section{Results}

More than 70 delegates attended the event at which 10 senior hospital staff presented. Speakers included the chief executive officer, the medical director, the chief financial officer and the chief operating officer.

Feedback was sought from attendees on their satisfaction with the course content and understanding of leadership and management as a result of the course. Of those delegates completing feedback, $95 \%$ rated the content as good or excellent, and $89 \%$ reported the course had improved their understanding of leadership and management roles in the hospital.

\section{Conclusion}

There is an appetite among registrar level doctors for leadership and management training and engagement with senior executive staff. There is also appetite from the trust to make this an annual event as the trust values the contribution junior doctors can make. This training will better equip future consultants in their leadership roles and furnish them with tools to navigate management meetings. Further courses are planned to address this locally as a result of this successful training day.

Author: Royal College of Physicians chief registrar, University Hospital Southampton NHS Foundation Trust, Southampton, UK

\section{Conflict of interest statement}

None declared. 